\title{
A survey of resuscitative endovascular balloon occlusion of the aorta (REBOA) program implementation in Canadian trauma centres
}

\author{
Sean Hurley ${ }^{1} \cdot$ Mete Erdogan $^{2} \cdot$ Jacinthe Lampron $^{3} \cdot$ Robert S. Green $^{1,2,4} \mathbb{( \mathbb { O }}$
}

Received: 24 May 2021 / Accepted: 6 August 2021 / Published online: 18 September 2021

(C) The Author(s), under exclusive licence to Canadian Association of Emergency Physicians (CAEP)/ Association Canadienne de Médecine d'Urgence (ACMU) 2021

\begin{abstract}
Objective To determine how many Level 1 and Level 2 trauma centres in Canada have implemented a resuscitative endovascular balloon occlusion of the aorta (REBOA) program, and to identify facilitators and barriers to successful implementation of REBOA programs.

Methods An electronic survey was developed and administered in November 2019 (updated in July 2021) via email to directors at all 32 Level 1 and Level 2 trauma centres across Canada, and to the medical director in PEI (no Level 1 or Level 2 capacity). Survey responses were supplemented by an online search in PubMed and the grey literature. Responses were analyzed using simple descriptive statistics including frequencies and proportions.

Results We received responses from directors at 22 sites (17 Level 1 trauma centres, 4 Level 2 trauma centres, PEI) for a response rate of $66.7 \%$. There are 6 Level 1 trauma centres with REBOA programs; all were implemented between 2017 and 2019. One additional Level 1 trauma centre that did not respond was found to have a REBOA program; thus, 21.9\% (7/32) of Canadian Level 1 and Level 2 trauma centres have an existing REBOA program. These programs are located in three provinces (British Columbia, Ontario, Quebec). Five other centres are planning on implementing a REBOA program in the next 2 years. The number of REBOA cases performed ranged from 0 to 30 (median 2). Factors contributing most to successful program implementation were having physician champions and patient populations with sufficient REBOA candidates, while cost and lack of expertise were the greatest barriers identified.

Conclusion As of July 2021, 21.9\% (7/32) of Canadian Level 1 and Level 2 trauma centres have a REBOA program. Physician champions and a patient population with sufficient numbers of REBOA candidates were the most important factors contributing to successful implementation of these programs.
\end{abstract}

Keywords Trauma $\cdot$ REBOA $\cdot$ Survey

Robert S. Green

greenrs@dal.ca

Sean Hurley

sean.hurley@dal.ca

Mete Erdogan

mete.erdogan@nshealth.ca

Jacinthe Lampron

jlampron@toh.ca

1 Department of Emergency Medicine, Dalhousie University, Halifax, NS, Canada

2 Nova Scotia Health Trauma Program, Nova Scotia Health, Halifax, NS, Canada

3 Department of Surgery, University of Ottawa, Ottawa, ON, Canada

4 Department of Critical Care, Dalhousie University, Halifax, NS, Canada 


\section{Résumé}

Objectifs Déterminer combien de centres de traumatologie de niveau 1 et de niveau 2 au Canada ont mis en œuvre un programme d'occlusion endovasculaire par ballonnet de l'aorte en réanimation (REBOA), et identifier les facilitateurs et les obstacles à la mise en œuvre réussie des programmes REBOA.

Méthodes Un sondage électronique a été élaboré et administré en novembre 2019 (mis à jour en juillet 2021) par courriel aux directeurs des 32 centres de traumatologie de niveau 1 et 2 au Canada, ainsi qu'au directeur médical de l'Î.-P.-É. (aucune capacité de niveau 1 ou 2). Les réponses à l'enquête ont été complétées par une recherche en ligne dans PubMed et la littérature grise. Les réponses ont été analysées à l'aide de statistiques descriptives simples, y compris les fréquences et les proportions.

Résultats Nous avons reçu des réponses des directeurs de 22 sites ( 17 centres de traumatologie de niveau 1, 4 centres de traumatologie de niveau 2, Î.-P.-É.), soit un taux de réponse de 66,7\%. Il existe 6 centres de traumatologie de niveau 1 avec des programmes REBOA ; tous ont été mis en œuvre entre 2017 et 2019. Un autre centre de traumatologie de niveau 1 qui n'a pas répondu s'est avéré avoir un programme de REBOA ; ainsi, 21,9\% (7/32) des centres de traumatologie canadiens de niveau 1 et de niveau 2 ont déjà un programme de REBOA. Ces programmes sont situés dans 3 provinces (ColombieBritannique, Ontario, Québec). Cinq autres centres prévoient de mettre en place un programme REBOA dans les 2 prochaines années. Le nombre de cas de REBOA effectués allait de 0 à 30 (médiane 2). Les facteurs contribuant le plus à une mise en œuvre réussie du programme étaient le fait d'avoir des médecins champions et des populations de patients avec suffisamment de candidats au REBOA, tandis que le coût et le manque d'expertise étaient les plus grands obstacles identifiés.

Conclusions En juillet 2021, 21,9\% (7/32) des centres canadiens de traumatologie de niveau 1 et 2 disposent d'un programme de REBOA. Les médecins champions et une population de patients avec un nombre suffisant de candidats au REBOA ont été les facteurs les plus importants contribuant à la réussite de la mise en œuvre de ces programmes.

\section{Clinician's capsule}

What is known about the topic?

Resuscitative endovascular balloon occlusion of the aorta (REBOA) is a potentially life-saving intervention in trauma patients with non-compressible subdiaphragmatic hemorrhage.

\section{What did this study ask?}

How many Level 1 and Level 2 trauma centres in Canada have implemented or are planning a REBOA program?

\section{What did this study find?}

REBOA programs exist at 7 centres across 3 provinces, and will be implemented at 5 additional centres within 2 years.

\section{Why does this study matter to clinicians?}

This study represents the first survey of REBOA use in Canada and highlights facilitators and barriers to REBOA program implementation.

\section{Introduction}

Resuscitative endovascular balloon occlusion of the aorta (REBOA) is a temporizing procedure for hemodynamically unstable patients with suspected sub-diaphragmatic hemorrhage prior to definitive surgical management or angiography [1]. Despite mixed evidence for REBOA clinical utilization [2, 3], trauma centres continue to implement REBOA programs. The first REBOA case in Canada was reported in 2015 at St. Michael's Hospital in Toronto [4], and other centres across the country have incorporated REBOA into their trauma resuscitation practices [5].

Currently, there are no data available regarding program implementation and utilization of REBOA in Canada. Our primary objective was to determine how many Canadian Level 1 and Level 2 trauma centres have implemented a REBOA program. As a secondary objective, we sought to identify facilitators and barriers to successful implementation.

\section{Methods}

\section{Study setting and design}

Canadian Level 1 trauma centres provide the majority of major trauma care in the trauma system and draw specialized trauma cases from neighboring regions that require services uniquely available at a Level 1 centre. If a system does not have a Level 1 trauma centre or has a major trauma caseload too large for a single Level 1 centre to handle, then a Level II trauma centre is required. Level 3 trauma centres typically exist in smaller urban or rural communities without timely access to Level 1 or Level 2 centres.

A cross-sectional survey was developed and administered using SelectSurvey (v5.01, ClassApps, Kansas City, 
MO, USA) in accordance with established guidelines [6]. In November 2019, the survey was sent electronically to directors at all 32 Level 1 and Level 2 trauma centres in 9 of the 10 provinces in Canada (population 37.6 million [2019]) as identified by Hameed and colleagues [7]. Any non-responders were followed up via email or phone in December 2019, February 2020, and May 2020. The survey was also sent to the medical director in the province of PEI which has a Level 3 trauma centre but no Level 1 or Level 2 capacity (patients are transported to trauma centres in neighboring New Brunswick or Nova Scotia). There are no Level 1 or Level 2 trauma centres in Canada's 3 territories (the Yukon, the Northwest Territories and Nunavut), and patients from these regions are transported to Level 1 trauma centres in British Columbia, Alberta, and Manitoba, respectively. An online search in PubMed and the grey literature (Google, Google Scholar) was conducted to identify any additional Canadian trauma centres performing REBOA, and we contacted directors at these centres to determine if they had implemented a REBOA program. The survey way updated in July 2021. Ethics approval was obtained from the Nova Scotia Health Research Ethics Board (File \#1024795).

\section{Data collection and analysis}

Survey questions are shown in Online Resource 1 . We collected data from directors on their position/title, institution, and presence/absence of a REBOA program (or planning for future program) at their centre. For centres with existing programs, we collected year of implementation, approximate number of REBOA cases, zones where REBOA catheters are placed, types of catheters used, qualifications/background of providers, training required to place REBOA catheters, and methods for maintaining the competency of those placing the catheters. We also asked respondents to rank (from most to least important) facilitators and barriers to successful implementation at trauma centres with REBOA programs, and perceived barriers to implementation at trauma centres without REBOA programs. Descriptive statistics including counts and proportions were used to analyze the responses.

\section{Results}

The survey was sent to 33 directors; we received 22 responses (66.7\% response rate). Medical directors were the most common respondents $(17 / 22 ; 77.3 \%)$ followed by administrative directors $(2 / 22 ; 9.1 \%)$, surgeons $(2 / 22$; $9.1 \%)$, and 1 research director $(1 / 22 ; 4.5 \%)$. Respondents represented trauma centres within all 10 Canadian provinces (Fig. 1), with the majority of respondents working at centres in Ontario (9/22; 40.9\%). A total of 17 Level 1 trauma centres and 4 Level 2 trauma centres were included, of which six centres currently have a REBOA program in place; all these programs were implemented at Level 1 trauma centres within the past 3 years. An online search identified 1 additional Level 1 trauma centre with a REBOA program (did not respond to survey, not included in analysis), for a total of 7 REBOA programs across the 32 Canadian Level 1 and Level 2 trauma centres (21.9\%). These programs are at trauma centres in the 3 most populous cities (Toronto, Montreal, Vancouver) and in southern Ontario. Five other centres in Alberta, Saskatchewan, and Ontario (4 Level 1 trauma centres, 1 Level 2 trauma centre) are planning to implement a REBOA program in the next 2 years.

Among six centres with an existing REBOA program, the number of REBOA cases performed to date ranged from 0 to 30 (median 2). Montreal General Hospital has performed approximately 30 cases total (expects $10-15$ per year) and Vancouver General Hospital has performed approximately 15-20 cases total (expects $10-15$ per year). REBOA cases were also performed at two centres currently without a REBOA program. The types of REBOA catheters used were predominantly Prytime ER-REBOA (5/6) and were placed in Zones 1 and 3 in 5 centres, and in Zone 3 at 1 centre. Trauma surgeons were identified as placing REBOA catheters in most centres, but trauma team leaders, emergency physicians, vascular surgeons, and critical care physicians also placed catheters in some centres. Competency was maintained by simulation (3/6) and case review (2/6). All six centres with existing programs (as well as 1 centre that has performed a few REBOA cases) enter data on REBOA cases into a registry for research and/or quality assurance purposes. Factors identified as contributing most to successful program implementation were local physician champions and a population with a sufficient number of patients who might benefit from REBOA, while cost and lack of expertise were the greatest barriers identified (Online Resource 2 -Table 1). At centres without a REBOA program $(n=16$, including PEI), insufficient number of patients who might benefit and lack of expertise were cited as the most important reasons for non-implementation.

\section{Discussion}

\section{Interpretation of findings}

This study represents the first cross-sectional survey of REBOA practice at trauma centres across Canada. Seven trauma centres in three provinces (accounting for 21.9\% of all Canadian Level 1 and Level 2 trauma centres) have implemented REBOA programs since 2017, with substantial distribution of REBOA cases performed at different centres. An additional 5 REBOA programs are planned 


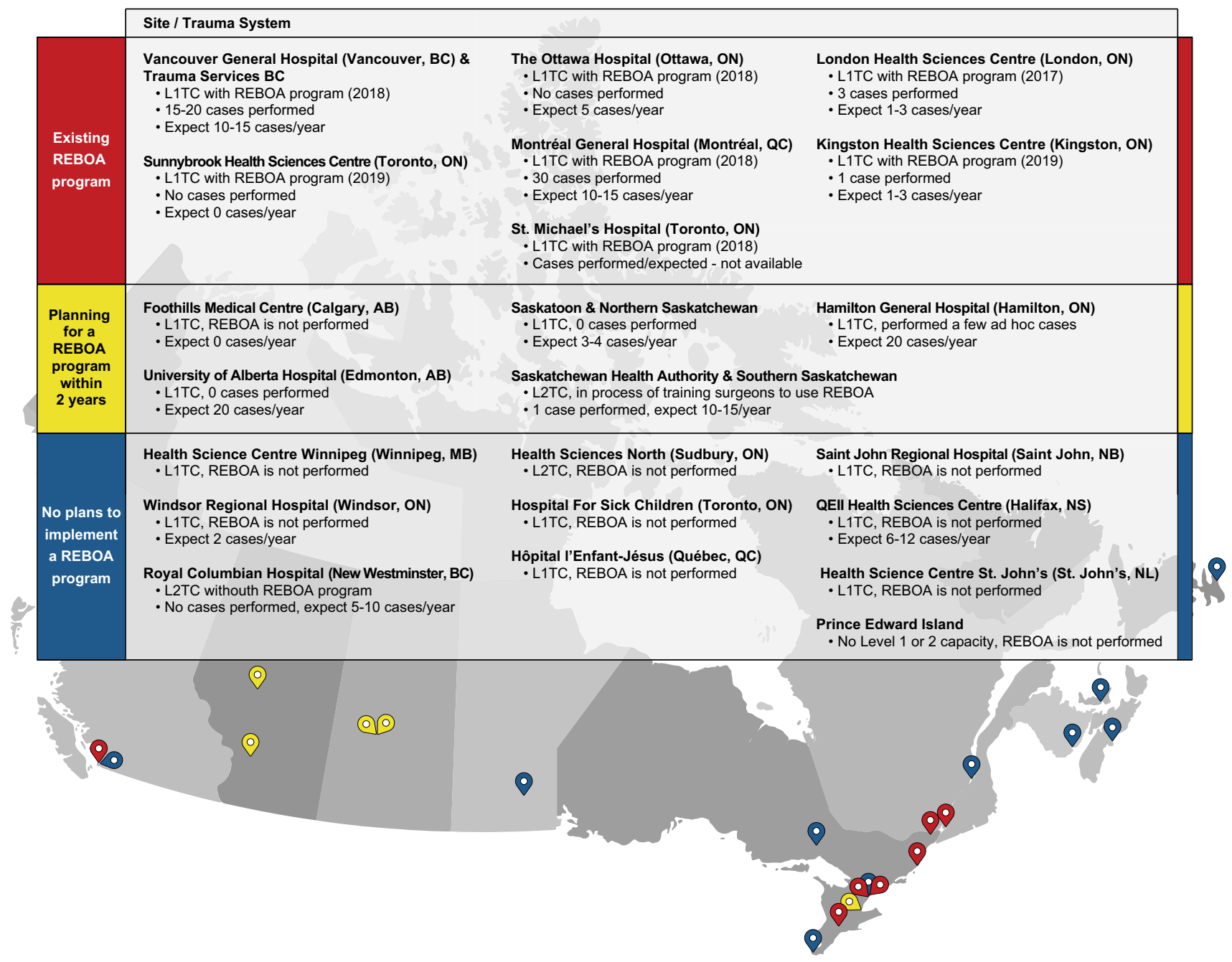

Fig. 1 Implementation of REBOA programs at Canadian Level 1 and Level 2 trauma centres. Survey was administered in November 2019 and updated in July 2021

for implementation in the near future at trauma centres in Alberta, Saskatchewan and Ontario. Physician expertise and the volume of potential candidates are key considerations as the practice of REBOA develops and expands across Canadian trauma centres.

\section{Comparison to previous studies}

There are no prior studies on the practice of REBOA at Canadian trauma centres. A recent study of 345 trauma surgeons in the United States found that $49.3 \%$ (170/345) had performed REBOA at least once within the past 2 years; $37.7 \%$ of respondents had an overall favorable opinion of REBOA, while $12.2 \%$ had an unfavorable opinion and $50.2 \%$ were undecided [8].

\section{Strengths and limitations}

This study is prone to non-response bias as we were unable to elicit responses from all Level 1 and Level 2 trauma centres, which limits the validity of our findings. We did attempt to maximize response rates with multiple follow-ups by email and phone to achieve a $66.7 \%$ response rate, and we supplemented the survey with an online search to identify any additional existing REBOA programs in Canada.

\section{Clinical implications}

Based on our findings, the most important factor why trauma centres did not have a REBOA program was insufficient number of potential REBOA patients. Recent gap analyses in Canada report that $1.1 \%$ of trauma patients in Alberta met criteria for REBOA [6], and in Nova Scotia, $1.5 \%$ of adult major trauma patients were REBOA candidates based on 
initial clinical presentation while and $0.5 \%$ were candidates based on anatomical injury patterns [9]. There are likely only a few trauma centres in Canada with adequate patient volumes to support the substantial costs, resources, and efforts required to start and maintain a REBOA program [5].

\section{Research implications}

At present, Canada does not have a national REBOA registry to track patient numbers and outcomes. For a rare procedure such as REBOA, a nationwide registry is an important tool for patient safety, quality improvement, and research purposes. Several registries exist in the United States and Japan $[2,10]$. Our study is the first to survey the REBOA practice at Canadian trauma centres, which is an important first step to coordinating a nationwide registry. Further research is warranted to determine the impact these REBOA programs have had on the outcomes of Canadian trauma patients.

\section{Conclusion}

There is a paucity of high-level evidence for REBOA use. In Canada, 21.9\% of Level 1 and Level 2 trauma centres have implemented a REBOA program. Physician champions and a suitable patient population were reported as the most important factors contributing to successful implementation of these programs.

Supplementary Information The online version contains supplementary material available at https://doi.org/10.1007/s43678-021-00193-w.

Acknowledgements The authors acknowledge Kate Mahon (Trauma Association of Canada) for assistance with identifying and contacting directors at Level 1 and Level 2 trauma centres.

Author contributions The study was conceived and designed by SH, ME and RG. All authors contributed to survey development. ME performed survey administration, data collection and analysis. All authors contributed to interpretation of the results. The manuscript was drafted by $\mathrm{SH}$. All authors were involved in critically reviewing the manuscript, provided final approval of the version submitted for publication, and have agreed to be accountable for all aspects of the work presented in the manuscript.

\section{Funding None.}

Availability of data and material Survey questions and responses are available upon request.

Code availability Not applicable.

\section{Declarations}

Conflict of interest The authors declare that they have no conflict of interest.
Ethics approval Ethics approval was obtained from the Nova Scotia Health Research Ethics Board (File \#1024795).

Consent to participate Consent was implied by completion of the survey.

Consent for publication Consent was implied by completion of the survey.

\section{References}

1. Thrailkill MA, Gladin KH, Thorpe CR, Roberts TR, Choi JH, Chung KK, et al. Resuscitative Endovascular Balloon Occlusion of the Aorta (REBOA): update and insights into current practices and future directions for research and implementation. Scand $\mathbf{J}$ Trauma Resusc Emerg Med. 2021;29:8. https://doi.org/10.1186/ s13049-020-00807-9.

2. Brenner M, Inaba K, Aiolfi A, DuBose J, Fabian T, Bee T, et al. Resuscitative endovascular balloon occlusion of the aorta and resuscitative thoracotomy in select patients with hemorrhagic shock: early results from the American Association for the Surgery of Trauma's aortic occlusion in resuscitation for trauma and acute care surgery registry. J Am Coll Surg. 2018;226:730-40. https://doi.org/10.1016/j.jamcollsurg.2018.01.044.

3. Manzano Nunez R, Naranjo MP, Foianini E, Ferrada P, Rincon E, García-Perdomo HA, et al. A meta-analysis of resuscitative endovascular balloon occlusion of the aorta (REBOA) or open aortic cross-clamping by resuscitative thoracotomy in non-compressible torso hemorrhage patients. World J Emerg Surg. 2017;12:30. https://doi.org/10.1186/s13017-017-0142-5.

4. Rice T, Ahmed N, Rezende-Neto J, Wheatcroft M, Prabhudesai V, Rizoli S. Proof of principle in a Canadian level I trauma centre: the use of resuscitative endovascular balloon occlusion of the aorta (REBOA). Can J Surg [Internet]. 2016;59(3 Suppl 1). http:// canjsurg.ca/wp-content/uploads/2017/01/59-3-S1.pdf. Accessed 10 May 2021

5. Eksteen A, O’Dochartaigh D, Odenbach J, Douma MJ, O’Neill $\mathrm{K}$, Anantha $\mathrm{R}$, et al. A gap analysis of the potential use of resuscitative endovascular balloon occlusion of the aorta (REBOA) in trauma at two major Canadian trauma centers. CJEM. 2021;23:36-44. https://doi.org/10.1007/s43678-020-00007-5.

6. Kelley K, Clark B, Brown V, Sitzia J. Good practice in the conduct and reporting of survey research. Int J Qual Health Care. 2003;15:261-6. https://doi.org/10.1093/intqhc/mzg031.

7. Hameed SM, Schuurman N, Razek T, Boone D, Van Heest R, Taulu T, Research Committee of the Trauma Association of Canada, et al. Access to trauma systems in Canada. J Trauma. 2010;69(6):1350-61. https://doi.org/10.1097/TA.0b013e3181 e751f7.

8. Sutherland M, Shepherd A, Kinslow K, McKenney M, Elkbuli A. REBOA use, practices, characteristics, and implementations across various US trauma centers. Am Surg. 2021. https://doi.org/ 10.1177/0003134820988813.

9. Hurley S, Erdogan M, Kureshi N, Casey P, Smith M, Green RS. Comparison of clinical and anatomical criteria for resuscitative endovascular balloon occlusion of the aorta (REBOA) among major trauma patients in Nova Scotia. CJEM. 2021. https://doi. org/10.1007/s43678-021-00100-3.

10. Matsumura Y, Matsumoto J, Kondo H, Idoguchi K, Ishida T, Kon Y, et al. Fewer REBOA complications with smaller devices and partial occlusion: evidence from a multicentre registry in Japan. EMJ. 2017;34:793-9. https://doi.org/10.1136/emerm ed-2016-206383. 